\title{
Kinetic Studies on the Optical Resolution of 2-Alkanol by Pseudomonas cepacia Lipase Catalyzed Transesterification with Vinyl Acetate in Organic Solvent
}

\author{
Masako OhNo $^{1}$, Naoki Kamo ${ }^{1}$, Takashi KiтAмото ${ }^{2}$, Naoya YamazATo $^{2}$, \\ Naoki HoshiBA ${ }^{2}$, Motomi Mayama ${ }^{2}$ and Hirofumi Hirata ${ }^{2 *}$ \\ ${ }^{1}$ Graduate School of Pharmaceutical Sciences, Hokkaido Univsersity \\ (Kita 12-Jo, Nishi 12-Chome, Kita-ku, Sapporo 060-0812, JAPAN) \\ ${ }^{2}$ Department of Bioscience and Technology, School of Engineering, Hokkaido Tokai University \\ (5-1 Minamisawa, Minami-ku, Sapporo 005-8601, JAPAN)
}

Edited by T. Itoh, Kitasato Univ., and accepted June 16, 2002 (received for review May 7, 2002)

\begin{abstract}
The optical resolution data were analyzed for Pseudomonas cepacia lipase (PCL) catalyzed transesterification between vinyl acetate and 2-alkanol in organic solvent. The plots of $\log E$ ( $E$ : the enantiomeric ratio as the reaction is irreversible) agaist the extent of conversion $(c)$ showed the maxima for all systems used. The competitive reaction in the optical resolution was verified by the analysis of the resolution data and an accordance of the enantiomeric excess (ee) vs. $c$ plots between racemic and optically pure alcohols. The reverse reaction in the optical resolution was experimentally proved by a decrease in optical purity for the reaction of optically pure 1-methylheptyl acetate and 2-octanol in the presence of PCL. The first order plot showed a lenearity for the reaction with $(R)$-2-octanol but curveture for the $(S)$ counterpart. Based on the above observations, we concluded that the transesterification with vinyl acetate did not obey the reported optical resolution equations because acetylation of the $(S)$ isomer in racemic 2-alkanol with the acetyl-enzyme intermediate was surpressed. Thus, $E$ increased with $c$ in the range of below 0.5 .
\end{abstract}

Key words: Pseudomonas cepacia lipase (PCL), transesterification, vinyl acetate, enantioselectivity $(E)$, kinetic study

\section{Introduction}

Vinyl acetate (VA) is a potential and practical acetylating reagent for the optical resolution of enantiomers in the racemate by lipase (triacylglycerol hydrolase, EC 3.1.1.3) catalyzed transesterification in organic solvent: VA irreversibly reacts with the active serine (Ser) residue in lipase to give the acetyl-enzyme intermediate [Enz-Ac] because vinyl alcohol is immediately converted to acetaldehyde by keto-enol tautomerization. This irreversibility is considered to accelerate the reaction rate. Such a reaction is called "irreversible transesterification" (1) and applied to the optical resolution of numerous secondary alcohols (1-5).

On the other hand, the analyses of optical resolution data are complicated for lipase catalyzed transesterification with VA. It is reported that the enantioselectivity [ $E$ : the enantiomeric ratio for the homocompetitive reaction (6-9), i.e., as the reaction is irreversible] at low conversion is greater than that at high conversion $(>50 \%)$ for Pseudomonas fluorescens lipase (PFL) catalyzed transesterification with racemic $\beta$-methyl-(2-

\footnotetext{
* Correspondence to: Hirofumi HiRaTA, Department of Bioscience and Technology, School of Engineering, Hokkaido Tokai University,

5-1 Minamisawa, Minami-ku, Sapporo 005-8601, JAPAN

E-mail: hirata@db.htokai.ac.jp
} 


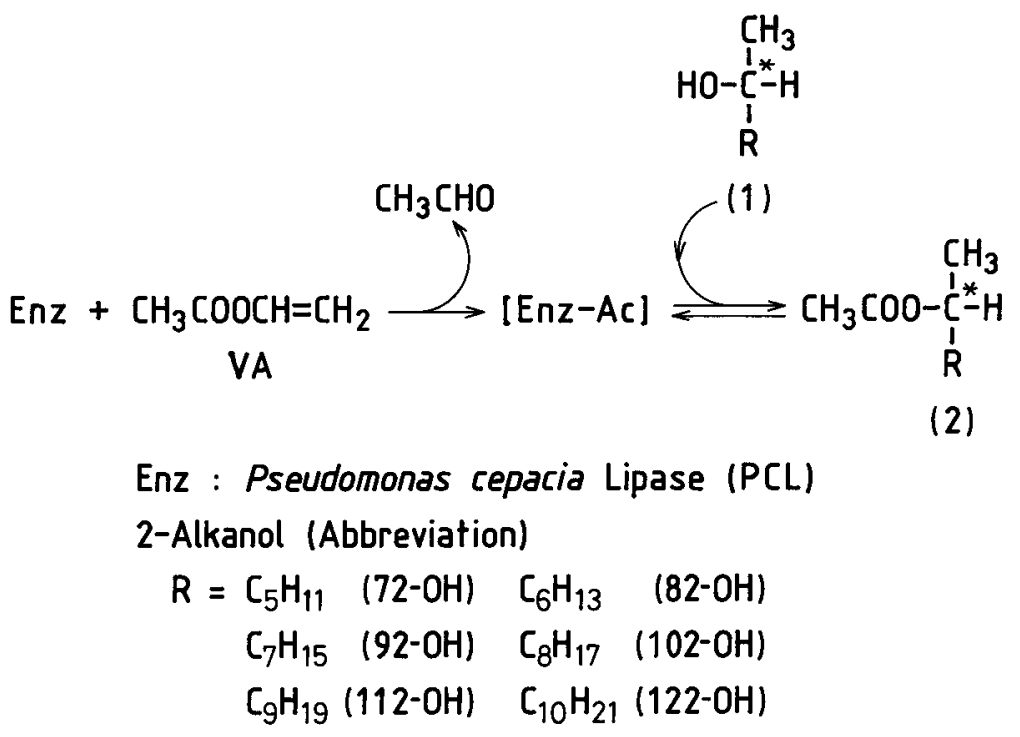

Scheme 1 Pseudomonas cepacia Lipase Catalyzed Transesterification between Vinyl Acetate (VA) and 2-Alkanol (1) in Organic Solvent.

thiophene)propanol in chloroform (10), which suggests that the reaction with VA is reversible. The notable observation is that the $E$ value increases as a function of substrate conversion $(<50 \%)$ for Pseudomonas cepacia lipase (PCL) catalyzed transesterification with $( \pm)-6$ methyl-5-hepten-2-ol (racemic sulcatol) in chlorinated solvents (11). Furthermore, we previously reported that the $E$ value is maximized agaist the extent of conversion (c) for PCL catalyzed transesterification with 2-alkanol (1) in organic solvent (12).

These led us to investigate the kinetic studies on the optical resolution by PCL catalyzed transesterification as shown in Scheme 1. The action of VA on the reaction was also compared to that of triacetylglycerol (TA) whose reaction is a reversible type (Scheme 2). In this paper, individual 2-alkanol was abbreviated to $\mathrm{X} 2-\mathrm{OH}$, where $\mathrm{X}$ is carbon number of the alcohol and 2- shows the position of hydroxy group (Scheme 1).

\section{Experimental}

\section{$\mathbf{2} \cdot \mathbf{1}$ Materials}

Vinyl acetate (VA, Wako Pure Chemical, Osaka) and triacetylglycerol (TA, Tokyo Chemical Industry, Tokyo) were dried over molecular sieves 3A (1/16, Wako Pure Chemical, Osaka) before use. 2-Alkanol (1) was purchased from Tokyo Chemical Industry, Tokyo [2-heptanol $(72-\mathrm{OH}) \sim 2$-undecanol (112-OH)] and Lancaster, Lancashire [2-dodecanol (122-OH)] and used as

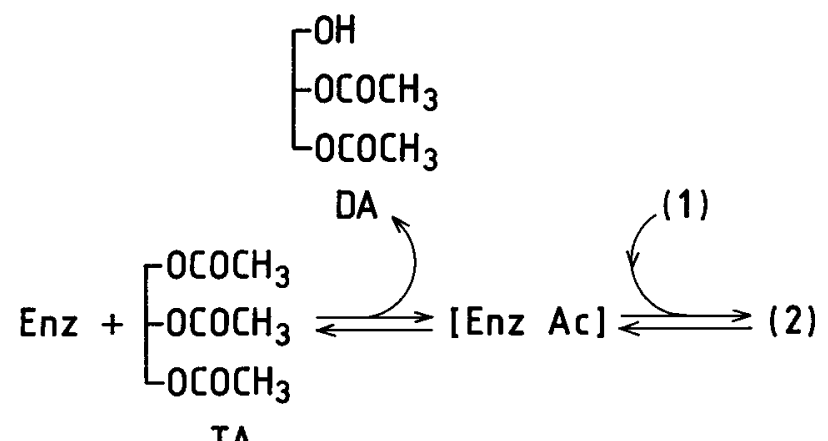

$T A$

Scheme 2 PCL Catalyzed Transesterification between Triacetylglycerol (TA) and (1) in Organic Solvent.

received. $(R)$-1-(1-naphthyl)ethyl isocyanate [ $R$-NEI, $e e>99 \%$, Tokyo Chemical Industry, Tokyo] and optically pure $(R)$ - and $(S)$-2-octanols $[(R)$ - and $(S)-82-\mathrm{OH}$, $e e>99 \%$, Chisso Chemical, Tokyo] were used as received. Silica gel (Silica gel 60, 70-230 mesh, Katayama Chemicals, Osaka) was used as received or after heating at $200^{\circ} \mathrm{C}$ for $2 \mathrm{~h}$ when the activity was not sufficient for the separation of the product and the unreacted substrate. Organic solvents were purified by the ordinary method (13) and dried over molecular sieves 3A. Pseudomonas cepacia lipase (PCL, Lipase PS, Amano, Nagoya, $43 \mathrm{U} / \mathrm{mg}$ for hydrolysis) was used as received. 


\subsection{Analytical Methods}

GC analysis was carried out by a Shimadzu 14B Gaschromatograph equipped with a FID detector (for the reaction with VA) and a Hitachi 263-80 Gaschromatograph equipped with a FID detector (for the reaction with TA). Column: G-100 column, $20 \mathrm{~m}, \phi 1.2 \mathrm{~mm}$, film thickness $1 \mu \mathrm{m}$ (purchased from GL Sciences, Tokyo); Injection and detector temperature: $250^{\circ} \mathrm{C}$. For the reaction with VA - Carrier $\left(\mathrm{N}_{2}\right)$ pressure: $40 \mathrm{kPa}$ $\left(80^{\circ} \mathrm{C}\right)$, Column temperature: $70 \rightarrow 120,80 \rightarrow 135,95$ $\rightarrow 150,110 \rightarrow 165,125 \rightarrow 165$ and $135 \rightarrow 195^{\circ} \mathrm{C}$ programmed with an increase of $10^{\circ} \mathrm{C} / \mathrm{min}$ for the reaction mixtures of $72-\mathrm{OH}, 82-\mathrm{OH}, 92-\mathrm{OH}, 102-\mathrm{OH}, 112-\mathrm{OH}$ and 122-OH, respectively. For the reaction of TA with 82-OH - Carrier speed $\left(\mathrm{N}_{2}\right): 30 \mathrm{~mL} / \mathrm{min}$; Column temperature: $70 \rightarrow 160^{\circ} \mathrm{C}$ programmed with an increase of $10^{\circ} \mathrm{C} / \mathrm{min}$.

HPLC analysis was performed by a JASCO (Japan Spectroscopic Co., Tokyo) Intelligent HPLC System equipped with a UV monitor. Column: combined two columns of Finepak SIL (particle size: $5 \mu \mathrm{m}$ ), $\phi 4.6 \times$ $250 \mathrm{~mm}$ (JASCO, Tokyo) or of Inertsil SIL (particle size: $5 \mu \mathrm{m}$ ), $\phi 4.6 \times 250 \mathrm{~mm}$ (GL Sciences, Tokyo); Mobile phase: dichloromethane containing 0.05 vol\% of methanol; Flow rate: $1 \mathrm{~mL} / \mathrm{min}$; Detection wavelength: $254 \mathrm{~nm}$.

The enantiomeric excess (ee) of enantiomerically enriched and optically pure alcohols, $(R)$ - and $(S)-(2)$, was determined as the corresponding diastereomers (carbamates) after derivatization with $(R)$-NEI (14). The optical purity of $(R)$-NEI was corrected by using $(R)$ and $(S)-82-\mathrm{OH}(e e=0.995)$ which were purchased or prepared in our laboratory by repeating the transesterification with VA in 1,2-dichloroethane.

The water content was measured by a Mitsubishi MCI Model-CA-02 Moisturemeter: PCL was 1.6-1.9 $\mathrm{wt} \%$ and the substrate solution was below $0.01 \mathrm{vol} \%$.

\subsection{Optical Resolution}

\section{$2 \cdot 3 \cdot 1 \quad$ Reaction of VA with (1)}

To a stirred solution (33-40 $\mathrm{mL})$ containing VA $(1.53-1.63 \mathrm{M})\left(1 \mathrm{M}=1 \mathrm{~mol} \mathrm{dm}^{-3}\right)$ and (1) $(0.39-0.88 \mathrm{M})$ at $30^{\circ} \mathrm{C}$ was added PCL $(30-100 \mathrm{mg} / \mathrm{mL}-s u b$. soln.). The reaction was followed by GC and terminated by filtration when it reached at the desired conversion. The enzyme was washed with two $20 \mathrm{~mL}$ portions of the solvent. Except the case of dioxane, the combined filtrates were evaporated. The residue was dissolved with
20-30 mL of benzene and loaded on the silica gel column (Silica gel 80-100 g, $\phi 30 \times 600 \mathrm{~mm}$ ). The compounds were eluted with benzene $(800-1000 \mathrm{~mL})$ and methanol $(300 \mathrm{~mL})$. In the case of dioxane, the combined filtrates were diluted with $300 \mathrm{~mL}$ of benzene, washed with three $100 \mathrm{~mL}$ portions of water, dried over anhydrous sodium sulfate and evaporated. The residue was treated by the same method as described above.

The benzene fractions $(300-800 \mathrm{~mL})$, which contained $(R)$-enriched ester $[(R)-(2)]$, were combined and evaporated. Yield: $65-95 \%$.

Alkaline solution ( $1 \mathrm{M} \mathrm{KOH} / 10 \% \mathrm{H}_{2} \mathrm{O}-\mathrm{C}_{2} \mathrm{H}_{5} \mathrm{OH}, 10$ $\mathrm{mL} / \mathrm{g}$-ester) was added to the $(R)$-enriched ester and the resulting mixture was left for $18-24 \mathrm{~h}$ at room temperature. A $100 \mathrm{~mL}$ of saturated sodium chloride solution (sat. $\mathrm{NaCl}$ ) was added to the mixture and the compounds were extracted with three $30 \mathrm{~mL}$ portions of hexane. The combined extracts were washed with three $30 \mathrm{~mL}$ portions of sat. $\mathrm{NaCl}$, dried over anhydrous sodium sulfate and evaporated to give the corresponding $(R)$ - enriched alcohol $[(R)-(\mathbf{1})]$. Yield: $60-90 \%$ [based on $(R)-(2)]$.

The methanol fractions $(300 \mathrm{~mL})$, which contained the unreacted alcohol, were concentrated until crystals of silica gel appeared. A $100 \mathrm{~mL}$ of sat. $\mathrm{NaCl}$ and $5 \mathrm{~mL}$ of the alkaline solution were added to the residue and the compounds were taken up by the same method for $(R)$-enriched (1), yielding the desired $(S)$-enriched alcohol [(S)-(1)]. Yield: 50-85\%.

$2 \cdot 3 \cdot 2$ Reaction of TA with 2-octanol (82-OH)

PCL $(100 \mathrm{mg} / \mathrm{mL}$-sub. soln.) was added to a stirred mixture $(35-40 \mathrm{~mL})$ of TA $(0.76-1.33 \mathrm{M})$ and $82-\mathrm{OH}$ (0.61-0.88 M) dissolved in 1,2-dichloroethane at $30^{\circ} \mathrm{C}$. The reaction mixture was filtered at the desired conversion (determined by GC) and the enzyme was washed with two $20 \mathrm{~mL}$ portions of 1,2-dichloroethane. The filtrates were combined and evaporated. The residue was dissolved with $30 \mathrm{~mL}$ of benzene and loaded on the silica gel column (Silica gel 80-100 g, $\phi 30 \times 600 \mathrm{~mm}$ ). When the residue exceeded $8 \mathrm{~g}$ of weight, it was divided into two equal portions, and each was dissolved with $30 \mathrm{~mL}$ of benzene and separately chromatographied. The compounds were eluted with benzene $(800 \mathrm{~mL})$ and methanol $(300 \mathrm{~mL})$.

The benzene fractions $(300-800 \mathrm{~mL})$ were combined and evaporated to give $(R)$-enriched 1-methylheptyl acetate $[(R)-82-\mathrm{OAc}]$ (Yield: 65-82\%), which was hydrolyzed by the same method as described above $(2$. 
$3 \cdot 1)$, yielding the corresponding $(R)$-enriched 2-octanol [(R)-82-OH]. Yield: 60-88\% [Based on $(R)-82-\mathrm{OAc}]$.

The methanol fractions $(300 \mathrm{~mL})$, which contained the unreacted alcohol, TA, diacetylglycerol (DA) and a small amount of monoacetylglycerol (MA), were concentrated. A $50 \mathrm{~mL}$ of the alkaline solution was added to the residue and the resulting mixture was left for $24 \mathrm{~h}$ at room temperature. TA, DA and MA were completely hydrolyzed, which was confirmed by GC. A $200 \mathrm{~mL}$ of sat. $\mathrm{NaCl}$ was added to the reaction mixture. The compounds were extracted with three $50 \mathrm{~mL}$ portions of hexane and the combined extracts were washed with three $50 \mathrm{~mL}$ portions of sat. $\mathrm{NaCl}$, dried over anhydrous sodium sulfate and evaporated to give $(S)$-enriched 2octanol [(S)-82-OH]. Yield: $68-85 \%$.

\subsection{Products}

$2 \cdot 4 \cdot 1 \quad$ Optically pure $(R)-1$-methylheptyl acetate

A mixture of optically pure $(R)-82-\mathrm{OH}(e e=0.995,62$ $\mathrm{mmol})$, VA (120 mmol), hexane $(50 \mathrm{~mL})$ and PCL (7.0 g) was stirred for $24 \mathrm{~h}$ at $30^{\circ} \mathrm{C}$ and filtered (conversion: quantitative). The enzyme was washed with two $25 \mathrm{~mL}$ portions of hexane and the combined filtrates were evaporated. The residue was divided two equal portions. Each was dissolved with $30 \mathrm{~mL}$ of benzene and separately chromatographied (Silica gel 100g, $\phi 30 \times 600$ $\mathrm{mm})$. The compounds were eluted with benzene. The ester fractions (300-800 mL) were combined and evaporated to give the desired optically pure $(R)$-1-methylheptyl acetate $[(R)-82-$ OAc $(e e=0.996)]$. Yield: $90 \%$.

$2 \cdot 4 \cdot 2$ Optically pure $(S)$-1-methylheptyl acetate

A mixture of optically pure $(S)-82-\mathrm{OH}(e e=0.995,62$ mmol), VA (120 mmol), hexane $(50 \mathrm{~mL})$ and PCL (7.0 g) was stirred for $4 \mathrm{~d}$ at $30^{\circ} \mathrm{C}$ (conversion: $90 \%$ ). The reaction mixture was treated with the same method as described above $(2 \cdot 4 \cdot 1)$, yielding the desired optically pure ester $[(S)-82-$ OAc $(e e=0.993)]$. Yield: $95 \%$.

\section{Results and Discussion}

\section{$3 \cdot 1$ Solvent Effect}

According to the optical resolution theory (7-9), the enantioselectivity ( $E$ : the enantiomeric ratio) is expressed as Eq. (1) when the reaction is reversible:

$$
\begin{aligned}
E & =\frac{\ln \left[1-(1+K) c\left(1+e e_{\mathrm{P}}\right)\right]}{\ln \left[1-(1+K) c\left(1-e e_{\mathrm{P}}\right)\right]} \\
& =\frac{\ln \left[1-(1+K)\left(c+e e_{\mathrm{S}}\{1-c\}\right)\right]}{\ln \left[1-(1+K)\left(c+e e_{\mathrm{S}}\{1+c\}\right)\right]}
\end{aligned}
$$

where $K$ is the equilibrium constant, $c$ is the extent of conversion, and $e e_{\mathrm{P}}$ and $e e_{\mathrm{S}}$ are the optical purities in enantiomeric excess of the product and the unreacted (recovered) substrate, respectively.

When the reaction is irreversible $(K=0)$, Eq. (1) is reduced to Eq. (2):

$$
\begin{aligned}
E & =\frac{\ln \left[1-c\left(1+e e_{\mathrm{P}}\right)\right]}{\ln \left[1-c\left(1-e e_{\mathrm{P}}\right)\right]} \\
& =\frac{\ln \left[(1-c)\left(1-e e_{\mathrm{S}}\right)\right]}{\ln \left[(1-c)\left(1+e e_{\mathrm{S}}\right)\right]}
\end{aligned}
$$

If $E$ is calculated by Eq. (2) for the reversible reaction, it will essentially decrease as $c$ increases (15). However, it is reported that $E$ can be determined by Eq. (2) in the range of $c$ where the reverse reaction is negligible even though the reaction is reversible (7).

First of all we screened more than a dozen of solvents for PCL catalyzed transesterification between VA and $(R S)-82-\mathrm{OH}$ at $30^{\circ} \mathrm{C}$. The results were summarized in Table 1. Since the plots of $\ln (1-c)$ agaist the reaction time $(t)$ showed a linearity at below $20 \%$ of conversion, the relative rate ( $=100$ in hexane) was calculated from the apparent first order rate constant. The $E$ values were determined by Eq. (2) using the optical resolution data $\left(e e_{\mathrm{P}}, e e_{\mathrm{S}}\right.$ and $\left.c\right)$ around 30 and $70 \%$ of conversions.

Table 1 showed that 1,2-dichloroethane, acetonitrile and acetone gave higher $E$ than the other solvents. A similar tendency is reported for PCL catalyzed reversible transesterification between tributyrylglycerol (TB) and secondary alcohol in organic solvent (16-18). An exciting and significant observation in Table 1 was that $E$ around $30 \%$ of conversion was smaller than that around $70 \%$ for both transesterifications in chlorinated (carbon tetrachloride) and nonchlorinated solvents (dioxane, tetrahydrofuran, acetone and acetonitrile). This suggests that $E$ increases with $c$, which is also supported by the fact that $E$ was almost comparable between 30 and $70 \%$ of conversions for several solvents (Table 1). 
Table 1 Solvent Effect on the Relative Rate and the Enantioselectivity $(E)$ for PCL Catalyzed Transesterification between VA and Racemic 2-Octanol [(RS)-82-OH] in Organic Solvent at $30^{\circ} \mathrm{C}$.

\begin{tabular}{cccccccccc}
\hline Solvent $^{\mathrm{a})}$ & Rate $^{\mathrm{b})}$ & $t / \mathrm{min}^{\mathrm{d})}$ & $c / \%^{\mathrm{d})}$ & $e e_{\mathrm{P}} / \%^{\mathrm{e})}$ & $E /-^{\mathrm{f})}$ & $t / \mathrm{h}^{\mathrm{d})}$ & $c / \%^{\mathrm{d})}$ & $e e_{\mathrm{S}} \%^{\mathrm{g})}$ & $\left.E /-^{\mathrm{f}}\right)$ \\
\hline Hex & $100^{\mathrm{c})}$ & 70 & 27 & 78 & 11 & 24 & 72 & 97 & 8 \\
Hep & 98 & 80 & 26 & 77 & 10 & 24 & 69 & 97 & 10 \\
Oct & 100 & 80 & 30 & 77 & 11 & 24 & 71 & 98 & 9 \\
i-Oct & 109 & 75 & 30 & 73 & 9 & 24 & 73 & 97 & 7 \\
c-Hex & 110 & 70 & 30 & 70 & 7 & 24 & 77 & 98 & 7 \\
PhH & 85 & 90 & 27 & 72 & 8 & 24 & 75 & 97 & 7 \\
Tol & 87 & 80 & 29 & 74 & 9 & 24 & 76 & 98 & 7 \\
TCM & 85 & 70 & 28 & 68 & 7 & 24 & 71 & 96 & 8 \\
DCE & 60 & 120 & 28 & 85 & 17 & 24 & 66 & 99 & 16 \\
DO & 44 & 150 & 31 & 71 & 8 & 24 & 70 & 98 & 10 \\
IPE & 82 & 80 & 31 & 73 & 9 & 24 & 80 & 97 & 6 \\
THF & - & 150 & 30 & 79 & 12 & 24 & 67 & 99 & 13 \\
DMK & - & 125 & 29 & 81 & 13 & 24 & 67 & 99 & 15 \\
MCN & 49 & 135 & 28 & 82 & 13 & 24 & 65 & 99 & 19 \\
\hline
\end{tabular}

a) Hex: hexane, Hep: heptane, Oct: octane, i-Oct: isooctane (2,2,4-trimethylheptane), c-Hex: cyclohexane, PhH: benzene, Tol: toluene, TCM: carbon tetrachloride, DCE: 1,2-dichloroethane, DO: dioxane, IPE: diisopropyl ether, THF: tetrahydrofuran, DMK: acetone, MCN: acetonitrile.

b) The relative rates were calculated from the initial rate constants at below $20 \%$ of conversion under $[\mathrm{VA}]=1.63 \mathrm{M},[82-\mathrm{OH}]=0.53 \mathrm{M}$ and $\mathrm{PCL}=30 \mathrm{mg} / \mathrm{mL}-\mathrm{sub}$. soln.

c) The initial rate constant was $2.2 \times 10^{-6} \mathrm{~s}^{-1} \mathrm{mg}^{-1} \mathrm{~mL}$.

d) The reaction time $(t)$ and conversion $(c / \%)$ under $[\mathrm{VA}]=1.53 \mathrm{M},[82-\mathrm{OH}]=0.88 \mathrm{M}$ and $\mathrm{PCL}=50 \mathrm{mg} / \mathrm{mL}-\mathrm{sub}$. soln.

e) Configuration of ester (2) was $(R)$.

f) The $E$ value was calculated from Eq. (2).

h) Configuration of the unreacted (recovered) alcohol was $(S)$.

\section{$3 \cdot 2$ Analyses of Optical Resolution Data}

In order to clarify the observation in Table 1, we analyzed the optical resolution data with use of Eq. (2) for the transesterification between VA and $(R S)-82-\mathrm{OH}$ in 1,2-dichloroethane and compared the reaction of VA with that of TA. The results were shown in Fig. 1. In the case of TA, $E$ was essentially independent of $c$ in the range of below 0.45 and sharply decreased with $c$ in the range of above 0.55 (Fig. 1B). The former observation suggests that $K$ in Eq. (1) is small and the latter demonstrates that the reaction is reversible. Analysis of the optical resolution data in Fig. 1B by Eq. (1) gave $E=18$ and $K=0.01$ except the plot at $c=0.73$. By contrast, $E$ increased at first, maximized around 0.5 of $c$ and then decreased with $c$ for the transesterification with VA (Fig. 1A). This is an interesting fact because such a feature has not been reported for the enzymatic reaction in organic solvent so far. The decrease in $E$ at higher $c$
$(>0.5)$ may be caused by the reverse reaction.

Table 1 predicts that $E$ is maximized agaist $c$ in all cases (chlorinated and nonchlorinated) for PCL catalyzed transesterification with VA. In order to prove it, we investigated the correlation between $\log E$ and $c$ for the transesterification between VA and 2-alkanol (1) using hexane, 1,2-dichloroethane and acetonitrile. The results were shown in Fig. 2. The $\log E$ vs. $c$ plots showed the maxima for all cases and their features were different depending on the substrate and solvent. It is remarkable and interesting that $E$ increases with $c$ in the range of below 0.5 for the reaction even in nonchlorinated solvents such as hexane and acetonitrile. (Fig. 2), because it is reported that $E$ is independent of $c(<0.5)$ for PCL catalyzed transesterification between VA and racemic sulcatol in nonchlorinated solvent (toluene) (11). This may be caused by the substrate structure. 


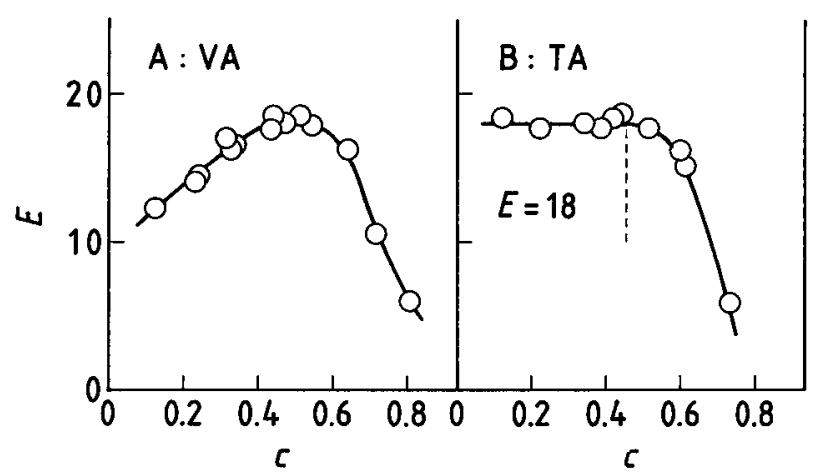

Fig. 1 Plots of the Enantioselectivity $(E)$ against the Extent of Conversion ( $c$ ) for PCL Catalyzed Transesterification with Racemic 2-Octanol (82-OH) in 1,2-Dichloroethane at $30^{\circ} \mathrm{C}$.

A: $[\mathrm{VA}]=1.08-1.63 \mathrm{M},[82-\mathrm{OH}]=0.53-0.88 \mathrm{M}$ and $\mathrm{PCL}=30-50 \mathrm{mg} / \mathrm{mL}-\mathrm{sub}$. soln., B: $[\mathrm{TA}]=0.76-1.33$ $\mathrm{M},[82-\mathrm{OH}]=0.61-0.88 \mathrm{M}$ and $\mathrm{PCL}=100 \mathrm{mg} / \mathrm{ml}-\mathrm{sub}$. soln. The $E$ values were determined by Eq. (2).

The resolution data in Fig. 1B fit Eq. (1) with $E=18$ and $K=0.01$ except $c=0.73$.

\section{$3 \cdot 3$ Competitive Reaction}

According to the optical resolution theory (6-9), enantiomers in the racemate competitively react with the acyl-enzyme intermediate to give the corresponding products for the enzymatic transesterification. This assumption will be proved if the resolution data fit either Eq. (1) or Eq. (2). Unfortunately, PCL catalyzed transesterification with VA fit neither Eq. (1) nor Eq. (2) [Figs. 1A and 2], although the reaction with TA obeyed Eq. (1) with $E=18$ and $K=0.01$ (Fig. 1B). We therefore investigated the competitive reaction in the optical resolution.

The competitive reaction in the enzymatic optical resolution is simply expressed as follows (7):

$$
\begin{aligned}
& \mathrm{A}+\mathrm{Enz} \rightleftarrows \mathrm{P}+\mathrm{Enz} \\
& \mathrm{B}+\mathrm{Enz} \rightleftarrows \mathrm{Q}+\mathrm{Enz}
\end{aligned}
$$

where $\mathrm{A}$ and $\mathrm{B}$ are the fast and slow reacting enantiomers in the racemate, and $\mathrm{P}$ and $\mathrm{Q}$ are the products

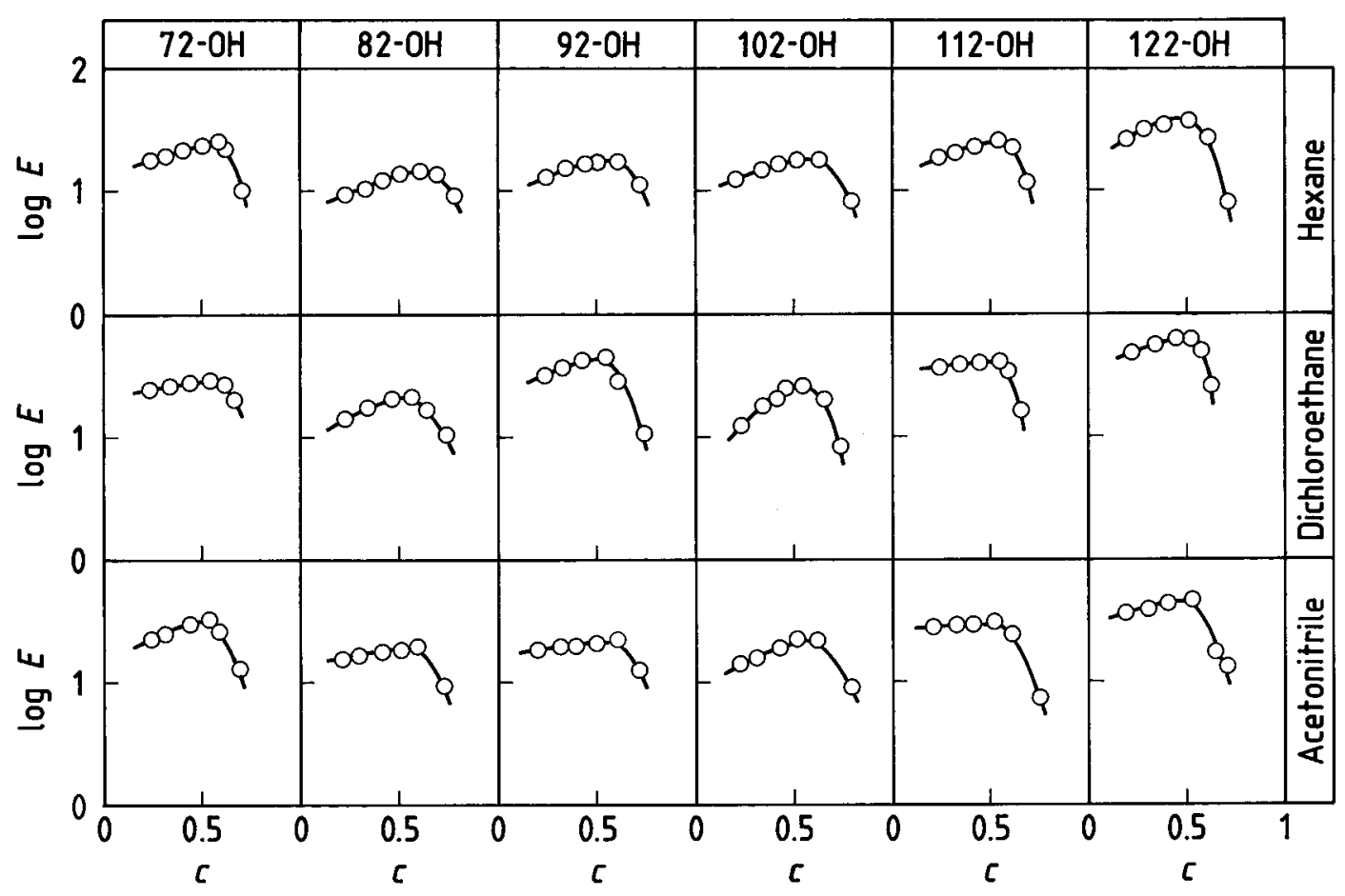

Fig. 2 Plots of $\log E$ against $c$ for PCL Catalyzed Transesterification between VA and Secondary Alcohol (1) in Organic Solvent at $30^{\circ} \mathrm{C}$.

$[\mathrm{VA}]=1.63 \mathrm{M},[72-\mathrm{OH}]=0.63 \mathrm{M},[82-\mathrm{OH}]=0.56 \mathrm{M},[92-\mathrm{OH}]=0.51 \mathrm{M},[102-\mathrm{OH}]=0.46 \mathrm{M},[112-$ $\mathrm{OH}]=0.42 \mathrm{M},[122-\mathrm{OH}]=0.39 \mathrm{M}$ and $\mathrm{PCL}=30-100 \mathrm{mg} / \mathrm{mL}$-sub. soln. The $E$ values were determined by Eq. (2). 
from $\mathrm{A}$ and $\mathrm{B}$, respectively. From the definitions of $e e_{\mathrm{P}}$, $e e_{\mathrm{S}}$ and $c$, one obtains

$$
\begin{aligned}
& e e_{\mathrm{P}}=\frac{[\mathrm{P}]-[\mathrm{Q}]}{[\mathrm{P}]+[\mathrm{Q}]} \\
& e e_{\mathrm{S}}=\frac{[\mathrm{B}]-[\mathrm{A}]}{[\mathrm{B}]+[\mathrm{A}]}
\end{aligned}
$$

and

$$
c=\frac{[\mathrm{P}]+[\mathrm{Q}]}{[\mathrm{A}]_{0}+[\mathrm{B}]_{0}}
$$

where $[\mathrm{A}],[\mathrm{B}],[\mathrm{P}]$ and $[\mathrm{Q}]$ are the concentrations of $\mathrm{A}$, $\mathrm{B}, \mathrm{P}$ and $\mathrm{Q}$ at time $t$ and $[\mathrm{A}]_{0}$ and $[\mathrm{B}]_{0}$ are the initial concentrations of $\mathrm{A}$ and $\mathrm{B}$, respectively.

From Eqs. (3)-(5), one obtains

$$
c_{\mathrm{A}}=c\left(1+e e_{\mathrm{P}}\right)=(1-c)\left(1-e e_{\mathrm{S}}\right)
$$

and

$$
c_{\mathrm{B}}=c\left(1-e e_{\mathrm{P}}\right)=(1-c)\left(1+e e_{\mathrm{S}}\right)
$$

where $c_{\mathrm{A}}$ and $c_{\mathrm{B}}$ are the extent of conversion for $\mathrm{A}$ and $\mathrm{B}$, respectively. Eqs. (6) and (7) predict that $c_{\mathrm{A}}$ and $c_{\mathrm{B}}$ can be determined from the optical resolution data. In the PCL catalyzed transesterification, $\mathrm{A}$ and $\mathrm{B}$ are $(R)$ and $(S)-(\mathbf{1})$, respectively.

Representative time courses of enantiomers in the racemate were shown in Fig. 3A for PCL catalyzed transesterification with VA and compared with those for TA (Fig. 3B). These demonstrate that both reactions are competitive with respect to the enantiomers. A similar competitive reaction (time course) was obtained from the data in Fig. 3A for the transesterification between VA and 2-alkanols $(72-\mathrm{OH} 122-\mathrm{OH})$ in hexane, 1,2-dichloroethane and acetonitrile.

Furthermore we tried to verify the competitive reaction using optically pure $(R)$ - and $(S)-82-\mathrm{OH}$ for the transesterification with VA. From Eqs. (3)-(5) and $[\mathrm{A}]_{0}=[\mathrm{B}]_{0}$, one obtains

$$
\begin{aligned}
e e_{\mathrm{P}} & =\frac{\left([\mathrm{P}] /[\mathrm{A}]_{0}\right)-\left([\mathrm{Q}] /[\mathrm{B}]_{0}\right)}{\left([\mathrm{P}] /[\mathrm{A}]_{0}\right)+\left([\mathrm{Q}] /[\mathrm{B}]_{0}\right)}=\frac{c_{\mathrm{R}}-c_{\mathrm{S}}}{c_{\mathrm{R}}+c_{\mathrm{S}}} \\
e e_{\mathrm{S}} & =\frac{\left([\mathrm{P}] /[\mathrm{A}]_{0}\right)-\left([\mathrm{Q}] /[\mathrm{B}]_{0}\right)}{2-\left\{\left([\mathrm{P}] /[\mathrm{A}]_{0}\right)+\left([\mathrm{Q}] /[\mathrm{B}]_{0}\right)\right\}} \\
& =\frac{c_{\mathrm{R}}-c_{\mathrm{S}}}{2-\left(c_{\mathrm{R}}+c_{\mathrm{S}}\right)}
\end{aligned}
$$

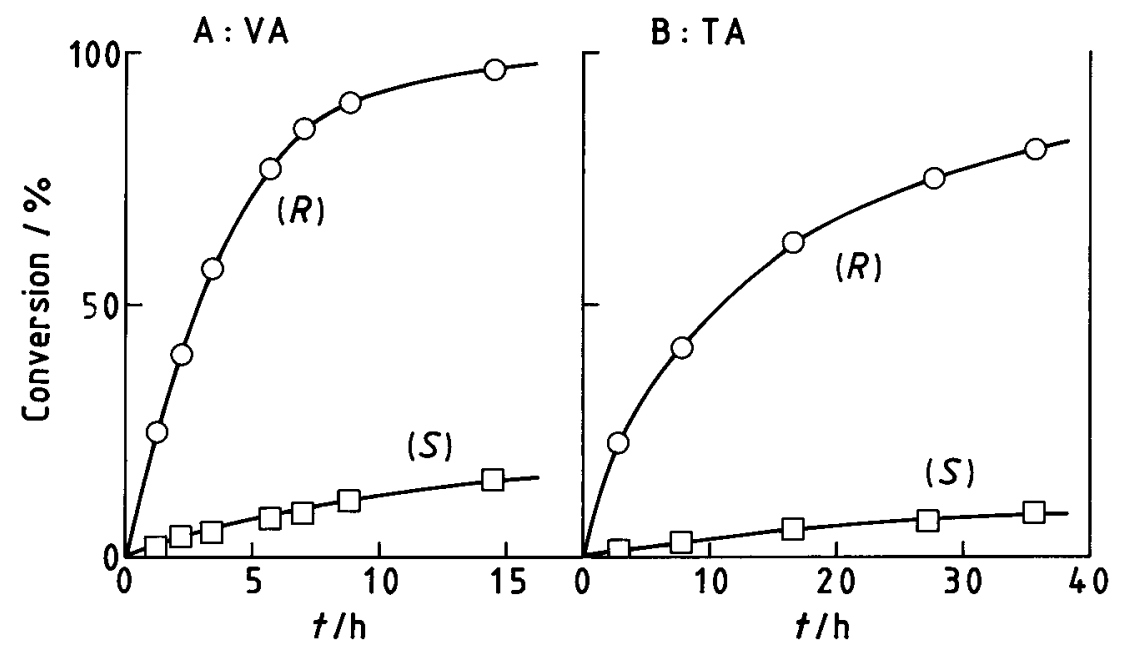

Fig. 3 Time Courses of Enantiomers in Racemic 2-Octanol for PCL Catalyzed Transesterification in 1,2-Dichloroethane at $30^{\circ} \mathrm{C}$.

A: $[\mathrm{VA}]=1.53 \mathrm{M},[82-\mathrm{OH}]=0.88 \mathrm{M}$ and $\mathrm{PCL}=50 \mathrm{mg} / \mathrm{mL}-\mathrm{sub}$. soln. B: $[\mathrm{TA}]=1.33 \mathrm{M},[82-\mathrm{OH}]=0.77 \mathrm{M}$ and $\mathrm{PCL}=100 \mathrm{mg} / \mathrm{ml}-\mathrm{sub}$. soln.

The conversions of the enantiomers were determined by Eqs. (6) and (7) using the optical resolution data $\left(e e_{\mathrm{P}}, e e_{\mathrm{S}}\right.$ and $\left.c\right)$. 
and

$$
c=\frac{c_{\mathrm{R}}+c_{\mathrm{S}}}{2}
$$

where $c_{\mathrm{R}}$ and $c_{\mathrm{S}}$ are the extent of conversion for the transesterification with optically pure $(R)$ - and $(S)$-82$\mathrm{OH}$, respectively. If the reaction is competitive with respect to the enantiomers, the plots of $e e$ agaist $c$ for the racemate should be in accordance with those determined by Eqs. (8)-(10) using the optically pure substrates. In fact, both plots showed an excellent agreement for the transesterification with VA as shown in Fig. 4. A similar agreement was also obtained for all transesterifications in Fig. 2.

Based on the above observations, we concluded that the transesterification with VA proceeds in a competitive manner as for TA (Fig. 1A) and TB (15).

\section{$3 \cdot 4$ Reverse Reaction}

As shown in Figs. 1A and 2, $E$ decreased with $c$ in the range of above 0.5 due to the reverse reaction. In the transesterification with VA, the reverse reaction is initi- ated by acetylation of the free active Ser residue in PCL with the product (2) to give the corresponding alcohol and the resulting acetyl-enzyme intermediate was attacked by the unreacted alcohol. As a result, the optical purities $\left(e e_{\mathrm{P}}\right.$ and $\left.e e_{\mathrm{S}}\right)$ should be diminished. In order to prove it, we examined the change in $e e$ for the reactions between optically pure 1-methylheptyl acetates $[(R)$ - and $(S)$-82-OAc] with 2-octanols $[(R)$ - and $(S)$-82$\mathrm{OH}]$ in the presence of PCL as the models for the reversibility (Scheme 3). They are also the models for the reverse reaction in the transesterification with TA. As shown in Tables $\mathbf{2}$ and $\mathbf{3}$, the ee values of esters and alcohols were obviously decreased after incubation. This demonstrates that either $(R)$ - or $(S)-82-\mathrm{OH}$ can act on the Ser residue in free PCL and that the former is a stronger acetylating reagent than the latter as expected.

\section{3·5 Kinetic Studies}

Our question is why $E$ increased with $c$ in the range of below 0.5 for PCL catalyzed transesterification with VA (Figs. 1A and 2). In order to clarify it, we examined the first order plots $[\ln (1-c) v s . t]$ of enantiomers for the transesterification with VA in 1,2-dichloroethane. Rep-

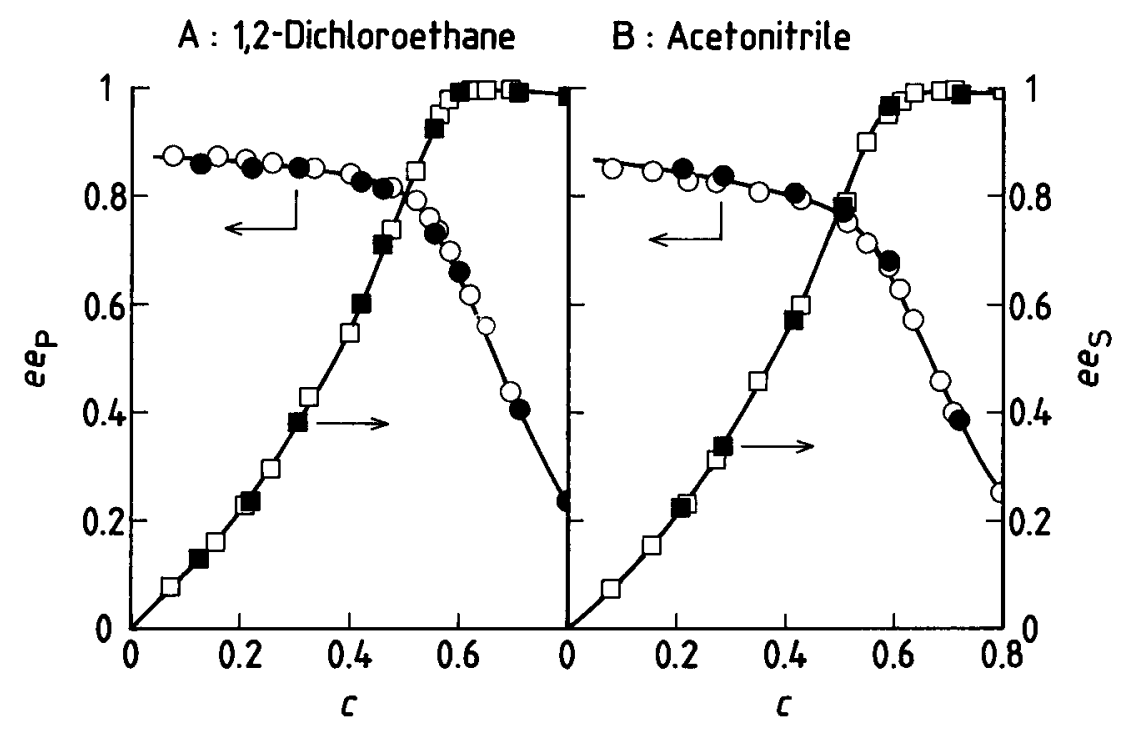

Fig. 4 Plots of ee vs. $c$ for PCL Catalyzed Transesterification between VA and Racemic and Optically Pure 2-Octanols in Organic Solvent at $30^{\circ} \mathrm{C}$.

$\bigcirc$ and $\square$ : the plots of $e e_{\mathrm{P}} v s . c$ and $e e_{\mathrm{S}} v s . c$ for the reactions with optically pure $(R)-$ and $(S)-82-\mathrm{OH}$, respectively. [VA] $=1.00 \mathrm{M},[(R)-82-\mathrm{OH}(e e=0.995)]=[(S)-82-\mathrm{OH}$ $(e e=0.995)]=0.57 \mathrm{M}, \mathrm{PCL}=100 \mathrm{mg} / \mathrm{mL}-\mathrm{sub}$. soln. The values of $e e_{\mathrm{P}}, e e_{\mathrm{S}}$ and $c$ were determined by Eqs. (8)-(10).

and $\square$ : the plots of ee $v s . c$ and $e e_{\mathrm{S}} v s . c$ for the reaction with racemic 2-octanol, respectively. [VA] $=1.53 \mathrm{M},[(R S)-82-\mathrm{OH}]=0.88 \mathrm{M}, \mathrm{PCL}=100 \mathrm{mg} / \mathrm{mL}-\mathrm{sub}$. soln. 


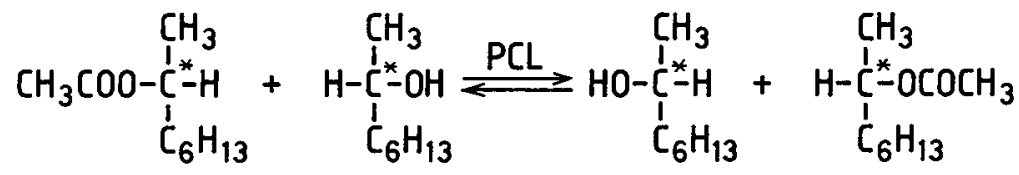

Scheme 3 PCL Catalyzed Reaction between Optically Pure 1-Methylheptyl Acetate $[(R)-$ or $(S)-82-\mathrm{OAc}]$ and 2-Octanol $[(S)$ - or $(R)-82-\mathrm{OH}]$ in Organic Solvent.

resentative results were shown in Fig. 5A. The first order plot of $(R)-82-\mathrm{OH}$ in $(R S)-82-\mathrm{OH}$ gave a linear correlation but curveture for the $(S)$ isomer. A similar result was obtained from the data in Fig. 2 and their time courses for the transesterification with VA. The first order plots were also examined for the reactions of VA with optically pure 2-octanols. Representative results were shown in Fig. 5B, which demonstrates the same tendency as those for the racemate (Fig. 5A). A similar result was observed for the reactions with optically pure 2-octanols in all solvents desribed in Table $\mathbf{1 .}$

In the transesterification with VA, the reation proceeds via

$$
\mathrm{Enz}+\mathrm{VA} \stackrel{k_{1}}{\longrightarrow} \mathrm{Enz}-\mathrm{Ac}+\mathrm{CH}_{3} \mathrm{CHO}
$$

and

$$
\mathrm{Enz}-\mathrm{Ac}+(\mathbf{1}) \stackrel{k_{2}}{\longrightarrow}(\mathbf{2})+\mathrm{Enz}
$$

where $k_{1}$ and $k_{2}$ are the rate constants. From Eqs. (11) and (12), one obtains

$$
\frac{\mathrm{d}[\mathbf{2}]}{\mathrm{d} t}=k_{2}[\mathrm{Enz}-\mathrm{Ac}][\mathbf{1}]=k_{\mathrm{a}}[\mathbf{1}]
$$

Table 2 PCL Catalyzed Reaction between Optically Pure $(R)-1$-Methylheptyl Acetate $[(R)-82-\mathrm{OAc}]$ with $(S)-2$ Octanol $[(S)-82-\mathrm{OH})]$ in Organic Solvent at $30^{\circ} \mathrm{C}^{\mathrm{a})}$.

\begin{tabular}{lccc}
\hline Solvent ${ }^{\mathrm{b})}$ & $t / \mathrm{h}$ & $\begin{array}{c}(R)-82-\mathrm{OAc} \\
e e\end{array}$ & $(S)-82-\mathrm{OH}$ \\
& & $e e$ \\
\hline Hex & 72 & 0.912 & 0.755 \\
DCE & 72 & 0.979 & 0.865 \\
MCN & 72 & 0.956 & 0.807
\end{tabular}

a) $[(R)-82-\mathrm{OAc}(e e=0.996)]=0.14 \mathrm{M},[(S)-82-\mathrm{OH}$ $(e e=0.995)]=0.19 \mathrm{M}, \mathrm{PCL}=100 \mathrm{mg} / \mathrm{mL}-\mathrm{sub}$. soln.

b) Abbreviations were described in Table 1. and

$$
[E n z]_{0}=[E n z]+[E n z-A c]
$$

where $k_{\mathrm{a}}$ is the apparent first order rate constant with respect to (1) and $[E n z]_{0}$ is the concentration of added PCL. The steady-state assumption on Enz-Ac gives

$$
\begin{aligned}
\frac{\mathrm{d}[\mathrm{Enz}-\mathrm{Ac}]}{\mathrm{d} t} & =k_{1}[\mathrm{VA}][\mathrm{Enz}]-k_{2}[\mathrm{Enz}-\mathrm{Ac}][\mathbf{1}] \\
& =0
\end{aligned}
$$

From Eqs. (13)-(15),

$$
k_{\mathrm{a}}=\frac{k_{1} k_{2}[\mathrm{VA}][\mathrm{Enz}]_{0}}{k_{1}[\mathrm{VA}]+k_{2}[\mathbf{1}]}
$$

is introduced.

If $k_{1}[\mathrm{VA}]>k_{2}[\mathbf{1}]$, i.e., Eq. (12) is rate-determing, Eq. (16) will be reduced to,

$$
k_{\mathrm{a}}=k_{2}[\mathrm{Enz}]_{0}
$$

which suggests that the first order plot should be a lin-

Table 3 PCL Catalyzed Reaction between Optically Pure $(S)$-1-Methylheptyl Acetate $[(S)-82-\mathrm{OAc}]$ with $(R)-2$ Octanol $[(R)-82-\mathrm{OH}]$ in Organic Solvent at $30^{\circ} \mathrm{C}^{\text {a) }}$

\begin{tabular}{lccc}
\hline Solvent $^{\mathrm{b})}$ & $t / \mathrm{h}$ & $(S)-82-\mathrm{OAc}$ & $(R)-82-\mathrm{OH}$ \\
& & $e e$ & $e e$ \\
\hline Hex & 72 & 0.944 & 0.948 \\
$\mathrm{DCE}$ & 72 & 0.989 & 0.981 \\
$\mathrm{MCN}$ & 72 & 0.982 & 0.976
\end{tabular}

\footnotetext{
a) $[(S)-82-\mathrm{OAc}(e e=0.993)]=0.14 \mathrm{M},[(R)-82-\mathrm{OH}$ $(e e=0.995)]=0.19 \mathrm{M}, \mathrm{PCL}=100 \mathrm{mg} / \mathrm{mL}-\mathrm{sub}$. soln.

b) Abbreviations were described in Table 1.
} 

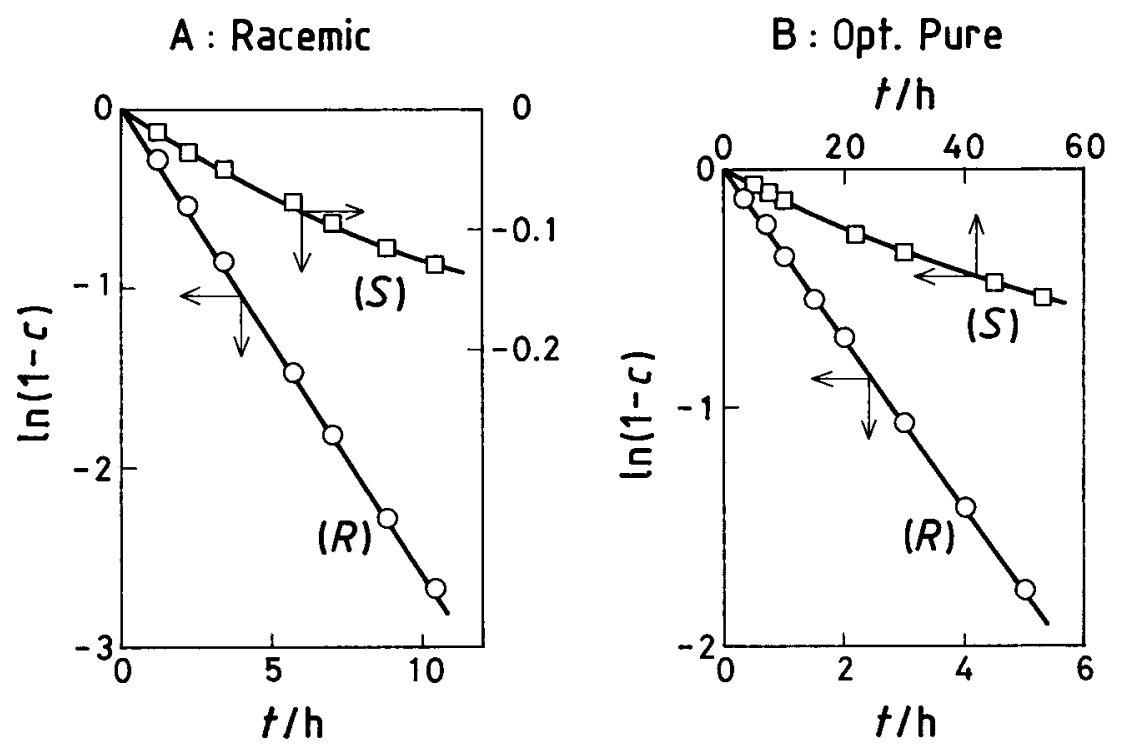

Fig. 5 The First Order Plots for PCL Catalyzed Transesterification between VA and Racemic and Optically Pure 2-Octanols in 1,2-Dichloroethane at $30^{\circ} \mathrm{C}$. A: the plots for enantiomers in $(R S)-82-\mathrm{OH}$. [VA] $=1.53 \mathrm{M},[(R S)-82-\mathrm{OH}]=0.88 \mathrm{M}$ and PLC $=50 \mathrm{mg} / \mathrm{mL}-\mathrm{sub}$. soln.

B: the plots for optically $(R)-$ and $(S)-82-\mathrm{OH}$. [VA] $=1.00 \mathrm{M},[(R)-82-\mathrm{OH}$ $(e e=0.995)]=[(S)-82-\mathrm{OH}(e e=0.995)]=0.57 \mathrm{M}$ and PLC $=100 \mathrm{mg} / \mathrm{mL}-\mathrm{sub}$. soln.

ear correlation. This is the case for $(R)-82-\mathrm{OH}$ as shown in Fig. 5. The assumption of $k_{1}[\mathrm{VA}]>k_{2}[\mathbf{1}]$ is reasonable bacause the rate for the reaction of VA with 1-octanol was much faster than that with $(R)-82-\mathrm{OH}$. These excluded the assumtion of $k_{1}[\mathrm{VA}]<k_{2}[1]$.

If $k_{2}[\mathbf{1}]$ is not negligible,

$$
\frac{1}{k_{\mathrm{a}}}=\frac{1}{k_{2}[\mathrm{Enz}]_{0}}+\frac{1}{k_{1}[\mathrm{Enz}]_{0}} \cdot \frac{[\mathbf{1}]}{[\mathrm{VA}]}
$$

is obtained from Eq. (17). In this paper, the reaction was conducted under $[\mathrm{VA}]>[\mathbf{1}]$. Thus, $[1] /[\mathrm{VA}]$ decreases as the reaction proceeds and $1 / k_{\mathrm{a}}$ should be decreased with $t$ because $k_{1}[E n z]_{0}>0$. This suggests that the time course should be a sigmoid, which was contrary to the results in Fig. 3.

Finally we examined the effects of additives on the transesterification rates for $(R)$ - and $(S)-82-\mathrm{OH}$ in 1,2dichloroethane. The results were summarized in Table 4. In this table, ethyl acetate and acetone were the model compounds of VA and acetaldehyde, and $(R)$ and $(S)-82-O A c$ were the products. Unfortunately no change in the rates was observed. A similar tendency is reported for PCL catalyzed reaction of VA with racemic sulcatol (11).
Based on the above observations, we concluded that acetylation of $(S)$ isomer in the racemate with the

Table 4 Effect of Additives on the Relative Rate for PCL Catalyzed Transesterification between VA and Optically Pure 2Octanols $[(R)$ - and $(S)-82-\mathrm{OH}]$ in $1,2-$ Dichloroethane at $30^{\circ} \mathrm{C}$ ).

\begin{tabular}{lcc}
\hline \multirow{2}{*}{ Additive } & \multicolumn{2}{c}{ Relative Rate/\% } \\
& $(R)-82-\mathrm{OH}^{\mathrm{b})}$ & $(S)-82-\mathrm{OH}^{\mathrm{c})}$ \\
\hline None & 100 & 100 \\
Acetone & $100 \pm 2$ & $101 \pm 5$ \\
Ethyl acetate & $98 \pm 2$ & $101 \pm 2$ \\
$(R)-82-\mathrm{OAc}$ & $99 \pm 2$ & $97 \pm 4$ \\
$(S)-82-\mathrm{OAc}$ & $99 \pm 2$ & $100 \pm 5$ \\
\hline
\end{tabular}

a) $[\mathrm{VA}]=0.46 \mathrm{M},\left[(R)-82-\mathrm{OH}\left(e e^{=0.995)}\right]=0.14 \mathrm{M}\right.$, $[(S)-82-\mathrm{OH}(e e=0.995)]=0.14 \mathrm{M},[(R)-82-\mathrm{OAc}$ $(e e=0.996)]=28 \mathrm{mM},[(S)-82-\mathrm{OAc}(e e=0.993)]=28$ $\mathrm{mM},[$ Acetone $]=[$ Ethyl acetate $]=0.042 \mathrm{vol} \%$, PCL $=50 \mathrm{mg} / \mathrm{mL}$-sub.soln.

b) The relative rates were calculated from the apparent first order rate constants.

c) The relative rates were calculated from the conversion at $t=1,2,3,4,5,6,7,8 \mathrm{~h}$ because the first order plots showed curveture (see Fig. 5). 
acetyl-enzyme intermediate [Eq. (12)] was surpressed during the reaction and thus $E$ increased with $c$ in the range of below 0.5 for the transesterification with VA. As a result, the optical resolution data did not fit the reported resolution equations [Eqs. (1) and (2)] as shown in Figs. 1A and 2.

\section{References}

1. Y.-F. WANG, J.J. LALONDE, M. MOMONGAN, D.E. BERGBREITER and C.-H. WONG, J. Am. Chem. Soc., Vol. 110, 7200-7205 (1988).

2. E. SANTANIELLO, P. FERRABOSCHI, G. GRISENTI and A. MANZOCCHI, Chem. Rev., Vol. 92, 1071-1140 (1992).

3. K. NAEMURA, J. Synth. Org. Chem. Jpn., Vol. 52, 49-57 (1994).

4. K. NAKAMURA and Y. HIROSE, J. Synth. Org. Chem. Jpn., Vol. 53, 668-677 (1995).

5. The recent papers in Tetrahedron:Asymmetry.

6. C.-S. CHEN, Y. FUJIMOTO, G. GIRDAUKAS and C.J. SIH, J. Am. Chem. Soc., Vol. 104, 7294-7299 (1982).

7. C.-S. CHEN, S.-H. WU, G. GIRDAUKAS and C.J. SIH, J. Am. Chem. Soc., Vol. 109, 2812-2817 (1987).

8. C.-S. CHEN and C.J. SIH, Angew. Chem. Int. Ed. Engl., Vol. 28 ,
695-707 (1989)

9. C.-S. CHEN and Y.-C. LIU, J. Jpn. Oil Chem. Soc., Vol. 41, 724-733 (1992).

10. M. LUNDH, O. NORDIN, E. HEDENSTÖRM and H.-E. HÖGBERG, Tetrahedron:Asymmetry, Vol. 6, 2237-2244 (1995).

11. F. SECUNDO, G. OTTOLINA., S. RIVA and G. CARREA, Tetrahedron:Asymmetry, Vol. 8, 2167-2173 (1997).

12. H. HIRATA, T. KITAMOTO, K. SEKIZAKI, N. INADA, K. YAMADA, M. MAYAMA and H. YANAGISHITA, Annual Meeting of Jpn. Oil Chem. Soc., (Nagoya) 2B-19 (1995).

13. J.A. RIDDICK and W.B. BUNGER, Organic Solvents. IV, Wiley-Interscience, New York, London, Sydney, Tronto (1970).

14. H. HIRATA, T. YAMASHINA, K. HIGUCHI, K. SAKAKI and I. IIDA, J. Jpn. Oil Chem. Soc., Vol. 40, 995-1001 (1991).

15. H. HIRATA, M. MAYAMA, N. INADA, K. YAMADA, H. YANAGISHITA and M. SUGIURA, J. Jpn. Oil Chem. Soc., Vol. 44, 1067-1074 (1995).

16. H. HIRATA, M. MIYAGISHI and M. MAYAMA, Nippon Kagaku Kaishi, Vol. 1998, 113-118 (1998).

17. H. HIRATA, M. MAYAMA, H. YANAGISHITA and M. SUGIURA, J. Jpn. Oil Chem. Soc., Vol. 47, 1217-1223 (1998).

18. H. HIRATA, M. MAYAMA, M. OHNO, N. KAMO and H. YANAGISHITA, Nippon Kagaku Kaishi, Vol. 2002, 147-154 (2002). 